This is an Open Access article, distributed under the terms of the Creative Commons Attribution licence (http://creativecommons.org/licenses/by/4.o/), which permits unrestricted re-use, distribution, and reproduction in any medium, provided the original work is properly cited.

doi:10.1017/So1 $44686 X_{1} 6000477$

\title{
Transition from community dwelling to retirement village in older adults: cognitive functioning and psychological health outcomes
}

\author{
CAROL HOLLAND*, ALEXIS BOUKOUVALAS*, \\ STUART WALLIS*, DANIELLE CLARKESMITH*, \\ RICHARD COOKE*, LEANNE LIDDELL* and AMANDA KAY*
}

\begin{abstract}
Supported living and retirement villages are becoming a significant option for older adults with impairments, with independence concerns or for forward planning in older age, but evidence as to psychological benefits for residents is sparse. This study examined the hypothesis that the multi-component advantages of moving into a supported and physically and socially accessible 'extra-care' independent living environment will impact on psychological and functioning measures. Using an observational longitudinal design, 161 new residents were assessed initially and three months later, in comparison to 33 older adults staying in their original homes. Initial group differences were apparent but some reduced after three months. Residents showed improvement in depression, perceived health, aspects of cognitive function and reduced functional limitations, while controls showed increased functional limitations (worsening). Ability to recall specific autobiographical memories, known to be related to social problem solving, depression and functioning in social relationships, predicted change in communication limitations, and cognitive change predicted changes in recreational limitations. Change in anxiety and memory predicted change in depression. Findings suggest that older adults with independent living concerns who move to an independent but supported environment can show significant benefits in psychological outcomes and reduction in perceived impact of health on functional limitations in a short period. Targets for focused rehabilitation are indicated, but findings also validate development of untargeted general supportive environments.
\end{abstract}

KEY WORDS - extra-care supported living, cognitive functioning, independence, active ageing, mental wellbeing.

* Aston Research Centre for Healthy Ageing, School of Life \& Health Sciences, Aston University, Birmingham, UK. 


\section{Introduction}

Internationally, there is a growing emphasis on promoting independence and improving quality of life and health outcomes for older people, e.g. following the United Kingdom (UK) government's Green Paper 'Independence, Wellbeing and Choice' (Department of Health 2005) or Europe 2020 initiatives. The European Innovation Partnership, launched in 2011 , aims to increase average healthy lifespan by two years by 2020 (European Commission 2011). This initiative includes enabling older people to live active and independent lives, and improving efficiency and sustainability of social and health-care systems, with the assumption of a need to provide successful interventions to ensure we remain healthy for as long as possible. While prevention of illness is a core focus of many such initiatives, prevention of loss of independence and promotion of active ageing even in the context of some difficulties is also an important focus.

Retirement villages are an important arena in which to promote supported, but independent, active ageing. Integrated support and the promotion of active lifestyles within these communities may help foster independence by sustaining physical and mental health and cognitive functioning. Villages usually offer a range of care and support services that respond to changing needs of residents over time (Croucher 2006), with many aiming to integrate some health care in the form of wellbeing monitoring and nurse-led day-to-day support coping with chronic illnesses. Most villages and schemes have domiciliary care available and support for people with cognitive impairments. Studies suggest that retirement villages have a general positive impact (e.g. Biggs et al. 200o). A more specific investigation of housing-with-care demonstrated long-term positive impacts on mortality, cognitive impairment and independence (using percentages improving or declining as a measure; Netten et al. 2011). However, little is known about the impact in the first few months for new residents, and there is little published data on the actual impacts in comparison to people who stay in their own homes. This study sets out to examine transition effects on a group of people moving into such housing-with-care environments.

When examining impact of transition from community to retirement village dwelling, it is also important to consider the inter-relationships between cognitive functioning and psychological health outcomes. Both anxiety and depression affect cognitive performance in all ages, but also stress is known to have a long-term negative effect on cognition, particularly executive function (Bunce and Murden 2006). Furthermore, depression is commonly implicated as a significant risk factor for dementia in older adults (e.g. da Silva et al. 2013). Reduction in depression or anxiety following settling in would therefore be expected to have a positive impact on cognitive 
functions, and a reduction in anxiety would be expected to predict reduction in depression or the likelihood of significant clinical depression (e.g. McLeod, Kessler and Landis 1992).

Retirement villages aim to provide an environment where social, physical and intellectual engagement forms part of everyday life, with classes, on-site gyms and increased accessibility. It is increasingly well-evidenced that a physically, intellectually and socially engaged lifestyle may slow cognitive decline, and improve function in healthy older adults, delay onset of dementia, reduce atrophy in memory-related brain regions (notably the hippocampus) and delay mortality (for a review, see Bennett et al. 2014). According to the Ontario Health Quality project 'Aging in the Community' (Health Quality 2008), social isolation is one of the main reasons older adults (over $6_{5}$ years of age) move into community living (the others being falls and injuries, incontinence issues and cognitive impairment-mainly dementia). As Kneale (2013) suggested, having a home within extra-care housing (Dawson, Williams and Netten 2006) may help ease the loneliness and social isolation of some older adults. Thus, older adults who make the transition to a socially engaging retirement community may benefit from measurable improvements to both mental health and cognitive functioning.

Aspects of cognitive functioning that have an impact on ability to engage positively are crucial to be able to make the most of opportunities for engagement. Autobiographical memory recall is a measure found to predict social problem solving, with ability to recall specific personally relevant events, as opposed to over-general memories, associated with the aetiology and recovery from depression, and with response or recovery in the context of traumatic events (Beaman et al. 2007). Both depression and older age have been found to impact this capacity to retrieve specific personal events, leading to a tendency to recall over-general memories (Holland and Rabbitt 1990; Holland et al. 2012; Piolino et al. 2002; Williams et al. 2007). Autobiographical memory is therefore proposed as a measure of functional memory (as opposed to measures of underlying cognitive efficiency such as working memory capacity) that may be reduced in older participants and be an important component of cognitive-emotional coping mechanisms, affecting ability to engage socially and to cope and compensate in the challenges that affect them, particularly in a new environment. For example, Bluck (2003) discuss the roles of autobiographical memory (AM) under the headings of (a) 'self' in terms of its use to provide continuity to a person's sense of self, or identity, over time and through transitions, (b) social, in terms of ability to develop intimacy and relationships, eliciting or providing empathy, and (c) directive, in terms of teaching or informing others or using memories of our past to plan or to think through future scenarios (Alea and Bluck 2003). However, a 
move to a new environment, with new social contacts, may have a positive influence on this measure, given that these uses of AM would be expected to be heightened during these months and therefore benefit from a practice effect. The relationship between this measure, psychological wellbeing and independent functioning will be examined in this investigation of transitions, with the hypothesis that changes in autobiographical memory would impact independence or function as assessed using instrumental activities of daily living (IADL) measures, or perceived functional limitations, using the functional limitations profile (FLP; Pollard and Johnston 2001). This measure assesses health status as perceived by the participant in terms of impact of any health issues on function, based on the original Sickness Impact Profile (Bergner, Bobbitt and Pollard 1981) defined as a 'behaviourally based measure of sickness related dysfunction' (Pollard and Johnston 2001: 922). It consists of a number of sub-components of limitations, and it is anticipated that the impact of changes in autobiographical memory and executive functions would be focused on sub-components of social, communication and recreation functions, that is, factors that enable social engagement.

Another aspect of cognitive function that commonly declines in older age is the function of the central executive of working memory. This has important implications for control and adaptation of attention in a variety of circumstances, such as planning, adapting and executing complex tasks. As such, cognitive assessments that include aspects of executive function, as well as attention and visuo-spatial skills needed for independence, will be emphasised, with the hypothesis that changes in executive function would influence changes in independence function or perceived limitations. The study focused on the approach generally described as extra-care housing, increasingly prevalent in the UK. This has the aim of meeting 'the housing, care and support needs of older people, while helping them to maintain their independence in their own private accommodation' (Netten et al. 2011:4). In the 13 different locations included in this study, provided by the ExtraCare Charitable Trust, there are additional services such as a 'wellbeing' advisor (a nurse) for health assessment and support, specific support for residents living with dementia or mild cognitive impairment (see Brooker et al. 2013), and an approach in which active engagement includes volunteering and leading activities, rather than simple provision. They are largely modern, purpose-built or adapted environments with attention paid to accessibility and community meeting areas such as coffee shops and village 'centres'.

This study aims to examine the impact of moving from the wider community into an active, socially accessible and supported retirement village. It is expected that older adults moving into active housing with care environments may be doing so because they perceive current or anticipated needs for support, and therefore differ from volunteer participants from amongst 
nearby community-dwelling older adults, but that their new socially accessible and supported communities may alleviate some of these differences and improve residents' outcomes. The analysis focuses on changes that occur in cognitive functioning and autobiographical memory, anxiety and depression, perceived health, ADLs and functional limitations, from when participants first move in to a three-month follow-up. The aim is to examine immediate impacts to inform the settling in period. Improving such outcomes has huge implications for quality of life and need for care, and so demonstrating these impacts as a result of the multi-component active supported environment has implications for sustainability and economic support both for housing with care itself, but also for more general concepts of supported independent active ageing, and of socially accessible neighbourhoods. Finally, if outcomes such as independence do change, exploration of potential predictors of such change will give an indication of which variables may be important to consider when developing more specific interventions.

\section{Hypotheses}

- Hypothesis 1: There will be initial differences between new residents and the control group on measures of cognitive functioning, psychological wellbeing, indicators of independence and functional limitations.

- Hypothesis 2: These differences will lessen after transition to the supported living environment, with residents showing improvement or stability, or the control group showing greater decline.

- Hypothesis 3: Outcome measures will change over time; these changes will be more positive for new residents compared with controls.

- Hypothesis 4: Where there are changes in depression, autobiographical memory or cognition, outcome independence (IADL) and functional limitations (FLP) will be impacted, with a focus on communication, social and recreational sub-components of functional limitations.

- Hypothesis 5: Where there are changes in anxiety, outcome depression will be impacted.

- Hypothesis 6: Where there are changes in depression and anxiety, outcome cognition function will be impacted.

\section{Method}

\section{Participants}

The study assessed 162 new residents, mean age 75.15 years (standard deviation $(\mathrm{SD})=8.16$ ) at baseline in comparison to a control group of 31 older adults, mean age 71.81 years $(\mathrm{SD}=6.3 \mathrm{O})$, who remained in their original homes. Controls were volunteers from a panel of local people who 


\section{Carol Holland et al.}

have volunteered to be on a database of people willing to participate in aspects of research at the university, living in the same or similar urban and suburban UK Midlands areas from which residents originated. The age difference is significant, $F(1,192)=4.5^{8}, p<0.05$ and so analyses are conducted controlling for age for variables that correlated with age (e.g. the cognitive variables). Inclusion criteria were (a) the person had moved into supported living within the last month and (b) had mental capacity to understand the participant information sheet, the longer-term involvement requirement and the consent form. The researchers who collected data from participants had all received training in mental capacity issues. Large print and more pictorial versions of information and consent forms were available. Consent was re-confirmed at each appointment. Population data from the villages indicated that 17 per cent of new residents took part. At the three-month follow-up, 136 residents remained in the study ( $16 \%$ attrition). Reasons for withdrawal were recorded where available: died $(3,1.9 \%)$, moved out $(1,0.6 \%)$, too ill at the time $(4,2.5 \%)$, found assessments too much $(7,4.3 \%)$, felt anxious about assessments $(2,1.2 \%)$, did not respond to contacts $(2,1.2 \%)$ and no reason given $(7,4.3 \%)$. Of the original 31 control participants, one $(3.2 \%)$ withdrew at the three-month stage (no reason given). This study forms part of a longitudinal project where volunteers complete further assessments 12 and 18 months after entry.

\section{Measures}

Researchers collected the following information:

1. The Addenbrooke's Cognitive Examination Revised (ACE-R; Mioshi et al. 2006): this includes attention/orientation, memory, verbal fluency, language and visuo-spatial awareness. The Mini-Mental State Examination (MMSE) score can be calculated from results. Fluency is used as an indicator of executive functioning.

2. The modified autobiographical memory test (AMT; Williams and Broadbent 1986). Participants were asked to retrieve different specific personal memories in response to ten cue words (five positive, five negative). The number of specific memories recalled out of the ten cues is used as the score, with different cues used at each assessment.

3. Hospital Anxiety and Depression Scale (Zigmond and Snaith 1983).

4. IADL scale (Lawton and Brody 1969) and basic activities of daily living (ADL; Katz et al. 1963) as measures of independence.

5. FLP, consisting of sub-constructs which can be accumulated to form a total FLP (Pollard and Johnston 2001). This is available on a sub- 
section of the total population given that the measure was added shortly after the initial data collection began $(\mathrm{N}=125)$. The measure is an updating of the Sickness Impact Profile and is a self-reported behavioural assessment. The sub-constructs investigated were ambulatory, mobility, household management, recreation, social, alertness, sleep and communication.

6. Self-perceived health was rated as: 'excellent, very good, good, fair or poor', which was converted to a numerical scale: $5=$ excellent, $1=$ poor. Perceived health is treated as an interval variable, as commonly used, based on meta-analysis indication of a dose-response pattern such that the probability of death is highest for the lowest category of 'poor', less for 'fair' and least for 'excellent' (Idler and Benyamini $1997)$.

\section{Procedure}

New residents entering 13 extra-care villages and smaller schemes in an 18 month period were given information about taking part in the study at their first residents' wellbeing assessment. Once they had read the information and had an opportunity to discuss with the wellbeing nurse and any carers, interested residents gave permission for researchers to contact them. Researchers made contact by telephone to discuss the study and arrange a meeting. Participants gave informed consent at the first meeting. Measures were administered either at the participant's place of residence or in a room within their village or scheme (as preferred). The complete assessment took approximately go minutes, including 15 minutes for introductions, participants' questions and consent. None of the measures are dependent upon time and volunteers were informed that they were welcome to ask for a break at any point. Control participants were sent a letter introducing the study, and those who volunteered were contacted, informed and consent taken in the same way. Most control volunteers came into the university for their appointments, although four with mobility impairments or busy schedules were visited in their homes.

\section{Analysis}

To determine whether there was a difference between groups at baseline and (separately) at the three-month stage, variables were compared using analysis of variance where data were normally distributed, or was acceptable following appropriate transformation. Square-root transformation was employed for anxiety and depression measures - while Tabachnick and Fidell (2007) recommend not transforming widely used measures 
because of the impact on interpretation, they also recommend transformation for ungrouped data, as in this context. To aid the interpretation of transformed data, Howell (1987) recommends conversion of transformed means back to original units and so this is the solution adopted here. For all tests, an alpha criterion value of $p \leqslant 0.05$ was used as the criterion for statistical significance. For screening measures (ACE-R, MMSE, IADL and FLP), data were considered to be censored. That is, true function for a large proportion of the population may be above ceiling level on subscales of the ACE-R, and on the MMSE and IADL. Although the overall ACE-R itself was not unduly censored, sub-scales were: Attention showed 70 per cent of participants at ceiling, Memory showed 20 per cent, Language showed $3^{6}$ per cent and Visuo-spatial showed $4^{1}$ per cent (see Table 1).

In addition, the true level of limitations may be below the basic floor level for FLP (33\% had no limitations on this measure). Table 1 gives uncorrected means and percentage censored (floor or ceiling) for screening variables to indicate which variables are censored. Wang et al. (20o8) suggest TOBIT models are particularly appropriate where 20 per cent or more of cases are at ceiling (or floor) on at least one occasion. Therefore, effects of group and time, including interactions, were examined using TOBIT models, also recommended by Piccinin et al. (2013), using the lmec software library version 1.o (Vaida, Fitzgerald and DeGruttola 2007). Given significant age difference between resident and control groups, effect of age was determined. Finally, hierarchical multiple regression analyses were used to determine which variables predicted change in outcomes, using SPSS (version 20).

\section{Results}

\section{Between-group differences}

To examine the hypothesis that residents would differ from controls in a negative direction initially, comparisons were made for each variable of interest, summarised in Tables 2 and 3 . No correction for multiple comparisons was made because the aim was to identify variables for which there is a difference between groups - not to test the null hypothesis of no overall difference between the groups (Armstrong 2014). Although this strategy increases the probability of a Type I error, it avoids inflating the probability of a Type II error. Since this is the first published study of the transition into extra-care residences, it is particularly important to avoid the exclusion of potentially relevant effects. The full $p$-value is given where significance is claimed to enable the reader to appraise the appropriateness of the conclusions further. To examine Hypothesis 2, that these differences will lessen 
T A в L E 1. Descriptive data for the censored screening variables

\begin{tabular}{|c|c|c|c|c|c|c|c|c|c|c|}
\hline & \multirow[t]{2}{*}{ Limit of measure } & \multirow[t]{2}{*}{ Percentage at lower limit } & \multirow[t]{2}{*}{ Percentage at upper limit } & \multirow[t]{2}{*}{ Group } & \multicolumn{3}{|c|}{ Baseline } & \multicolumn{3}{|c|}{$\begin{array}{l}\text { Three-month follow- } \\
\text { up }\end{array}$} \\
\hline & & & & & $\mathrm{N}$ & Mean & SD & $\mathrm{N}$ & Mean & SD \\
\hline MMSE & 30 & & 32 & $\begin{array}{l}\text { Residents } \\
\text { Control }\end{array}$ & $\begin{array}{r}160 \\
31\end{array}$ & $\begin{array}{l}27.28 \\
28.87\end{array}$ & $\begin{array}{l}3.61 \\
1.28\end{array}$ & $\begin{array}{r}143 \\
32\end{array}$ & $\begin{array}{l}27.45 \\
29.00\end{array}$ & \\
\hline \multirow[t]{2}{*}{ ACE- ${ }^{1}$} & 100 & & 1.85 & Residents & $\begin{array}{r}51 \\
160\end{array}$ & 83.95 & 13.64 & $\begin{array}{r}52 \\
143\end{array}$ & $85 \cdot 36$ & 14 \\
\hline & & & & Control & $3^{1}$ & 92.77 & $5 \cdot 10$ & 32 & $93 \cdot 94$ & $17 \circ^{\circ}$ \\
\hline \multirow[t]{2}{*}{ Attention } & 18 & & 70 & Residents & 160 & 16.98 & 2.29 & 143 & 17.01 & 2.4 \\
\hline & & & & Control & $3^{1}$ & 17.71 & 0.59 & 32 & $17 \cdot 75$ & \\
\hline \multirow[t]{2}{*}{ Memory } & 26 & & 20 & Residents & 160 & 20.10 & 5.10 & 143 & 21.43 & \\
\hline & & & & Control & $3^{1}$ & 24.26 & 1.87 & $3^{2}$ & 24.25 & \\
\hline \multirow[t]{2}{*}{ Fluency } & 14 & & 8 & Residents & 160 & $9 \cdot 53$ & 3.13 & 143 & $9 \cdot 45$ & \\
\hline & & & & Control & $3^{1}$ & 11.26 & $2.5^{6}$ & 32 & 11.72 & \\
\hline \multirow{2}{*}{ Language } & 26 & & $3^{6}$ & Residents & 160 & 23.44 & 3.59 & 143 & 23.41 & \\
\hline & & & & Control & $3^{1}$ & $24 \cdot 5^{2}$ & 2.01 & 32 & 24.84 & \\
\hline \multirow{2}{*}{$\begin{array}{l}\text { Visuo- } \\
\text { spatial }\end{array}$} & 16 & & $4^{1}$ & Residents & 160 & $13 \cdot 73$ & 2.82 & 143 & 13.98 & \\
\hline & & & & Control & 31 & 15.03 & 1.22 & 32 & 15.28 & \\
\hline \multirow[t]{2}{*}{ IADL } & 8 & & $5^{\circ}$ & Residents & 162 & 6.44 & 2.33 & 144 & 6.33 & 2. \\
\hline & & & & Control & $3^{1}$ & $7 \cdot 97$ & 0.18 & 32 & 7.97 & \\
\hline \multirow[t]{2}{*}{$\mathrm{ADL}$} & 6 & & 77 & Residents & 162 & 5.20 & 1.62 & 134 & $5 \cdot 3^{8}$ & \\
\hline & & & & Control & $3^{1}$ & 6.00 & 0.00 & 30 & 6.00 & \\
\hline \multirow[t]{2}{*}{ FLP total } & o & 33 & & Residents & 125 & $299 \cdot 39$ & 231.95 & 131 & 261.76 & 227 \\
\hline & & & & Control & $3^{1}$ & 59.23 & 120.05 & 32 & 131.64 & 169. \\
\hline
\end{tabular}

Notes: $\mathrm{N}$ varies slightly across variables because participants sometimes (but rarely) declined to complete part of an assessment, or for functional limitations profile (FLP) because the measure was applied to a subset of participants. SD: standard deviation. MMSE: Mini-Mental State Examination. ACE-R: Addenbrookes Cognitive Examination Revised. IADL: instrumental activities of daily living. ADL: basic activities of daily living. 1. The overall ACE-R was not censored, but indicated sub-components were. 
$\mathrm{T}_{\mathrm{A} \mathrm{B} \mathrm{L}}$ 2. Means and analysis of differences between residents and controls at baseline and three months

\begin{tabular}{|c|c|c|c|c|c|c|c|c|c|}
\hline & \multirow[t]{2}{*}{ Group } & \multicolumn{4}{|c|}{ Baseline } & \multicolumn{4}{|c|}{ Three-month follow-up } \\
\hline & & $\mathrm{N}$ & Mean & SD & $F, p\left(\right.$ partial eta $\left.{ }^{2}\right)$ & $\mathrm{N}$ & Mean & $\mathrm{SD}$ & $F, p\left(\right.$ partial eta $\left.{ }^{2}\right)$ \\
\hline \multirow[t]{2}{*}{ Perceived health } & Residents & 162 & 2.79 & 1.02 & $47.30, p<0.001(0.20)$ & 144 & 3.00 & 1.10 & $19.03, p<0.001(0.10)$ \\
\hline & Control & 31 & 4.12 & 0.81 & & 32 & 4.00 & 1.02 & \\
\hline \multirow[t]{2}{*}{ Anxiety $^{1}$} & Residents & 161 & 4.91 & & $9.37, p=0.003(0.05)$ & 143 & 4.28 & & $2.82, p=0.095(0.02)$ \\
\hline & Control & 31 & 2.72 & & & 32 & 3.11 & & \\
\hline \multirow[t]{2}{*}{ Depression $^{1}$} & Residents & 161 & 2.86 & & $16.83, p<0.001(0.08)$ & 143 & 2.45 & & $7.99, p=0.005(0.04)$ \\
\hline & Control & 31 & 1.00 & & & 32 & 1.13 & & \\
\hline \multirow[t]{2}{*}{ AMT } & Residents & 161 & 5.38 & 2.69 & $15.80, p<0.001(0.08)$ & 141 & 5.48 & 2.53 & $7.29, p=0.008(0.04)$ \\
\hline & Control & $3^{1}$ & $7 \cdot 55$ & 1.66 & & $3^{2}$ & 6.97 & 2.39 & \\
\hline
\end{tabular}

Notes: Results are of one-way analyses of variance; for the autobiographical memory test (AMT) this is analysis of covariance, controlling for age. N varies slightly across variables because participants sometimes (but rarely) declined to complete part of an assessment. SD: standard deviation. 1. Data were analysed using a square root transformation. The means reported are conversions of the transformed means back to original units for ease of interpretation (Howell 2007); as such, reporting SD values is inappropriate. 
T A в L E 3. Cross-sectional comparisons between groups at baseline and three months

\begin{tabular}{|c|c|c|}
\hline Measure & Baseline & Three-month \\
\hline & \multicolumn{2}{|c|}{$\operatorname{MLE}(95 \%$ CI) } \\
\hline MMSE & $1.69\left(-0.12,3.5^{0}\right)$ & $1.80(-0.09,3.69)$ \\
\hline ACE-R & $8.18(3.19,13.17)^{*}$ & $6.92(1.88,11.97)^{*}$ \\
\hline Attention & $1.03(-1.90,3.96)$ & $1.53(-0.64,3.69)$ \\
\hline Memory & $5.18(2.93,7.43)^{*}$ & $3.39(0.83,5.94)^{*}$ \\
\hline Fluency & $1.73\left(0.4^{2}, 3.03\right) *$ & $1.76(0.59,2.93) *$ \\
\hline Language & $0.95(-1.00,2.90)$ & $2.12(0.26,3.99)^{*}$ \\
\hline Visuo-spatial & $1.82(0.19,3.45) *$ & $1.72(-0.05,3.49)$ \\
\hline IADL & $7.34\left(3.3^{8}, 11.31\right)^{*}$ & $7.22(3.45,11.00)^{*}$ \\
\hline FLP total & $-417.10(-553.46,-280.75) *$ & $-162.40(-287.89,-36.91) *$ \\
\hline \multicolumn{3}{|l|}{ FLP component: } \\
\hline Ambulatory & $-79.82(-110.70,-48.94) *$ & $-65.13(-99.87,-30.39) *$ \\
\hline Mobility & $-289.16\left(-375^{6.24}, 3^{1} 77.92\right)$ & $-5^{8.25}(-92.11,-24.39) *$ \\
\hline Household management & $-316.93(-3905.79,3271.93)$ & $-28.32(-61.72,5.09)$ \\
\hline Social & $-67.27\left(-101.97,-32.5^{8}\right)^{*}$ & $-20.24(-50.86,10.38)$ \\
\hline Recreational & $-64.02\left(-102.5^{1},-25.5^{2}\right)^{*}$ & $-39.69(-73.02,-6.36) *$ \\
\hline Alertness & $-87.49\left(-145 \cdot 5^{8},-29 \cdot 4^{0}\right)^{*}$ & $-18.27(-79.21,42.67)$ \\
\hline Sleep & $-106.84(-157.84,-55.85)^{*}$ & $-32.35(-72.65,7.96)$ \\
\hline Communication & $-74.89(-128.47,-21.31)^{*}$ & $-29.4^{1}(-82.70,23.87)$ \\
\hline
\end{tabular}

Notes: Maximum likelihood estimate (MLE) and estimated 95 per cent confidence interval (95\% CI) are for the group effect. MMSE: Mini-Mental State Examination. ACE-R: Addenbrookes Cognitive Examination Revised. IADL: instrumental activities of daily living. FLP: functional limitations profile.

Significance: * significant effect (that is where o is not between the two bounds of the CI).

after transition to the supported living environment, these comparisons are repeated at the three-month time-point.

Where age is significantly correlated with the variable, this is controlled for by entering it as a covariate, given the age difference between the groups, which was only the case for the AMT in Table 2. For ADL, there is very high censoring overall, and complete censoring for the control group, so it is not analysed further.

There were age effects for all cognitive variables, but not for functional limitations or IADLs. Table 3 gives results of the cross-sectional TOBIT model, controlling for effects of age (see also Table 5). The coefficients (maximum likelihood estimates (MLEs) ) cannot be interpreted directly in the units of the measure, as is typically done in linear regression with normally distributed outcomes, because the measure was limited (truncated) by the censoring observed. To put it simply, this analysis extends the range of the outcomes. For example, for IADL the range is $(0,8)$ with $5^{\text {o per cent of }}$ the cohort hitting the maximum value. The magnitude of the difference between the two groups at baseline $(7.34 ; 95$ per cent confidence interval $(95 \% \mathrm{CI})=3.38,11.31)$ reflects the difference in the average IADL 


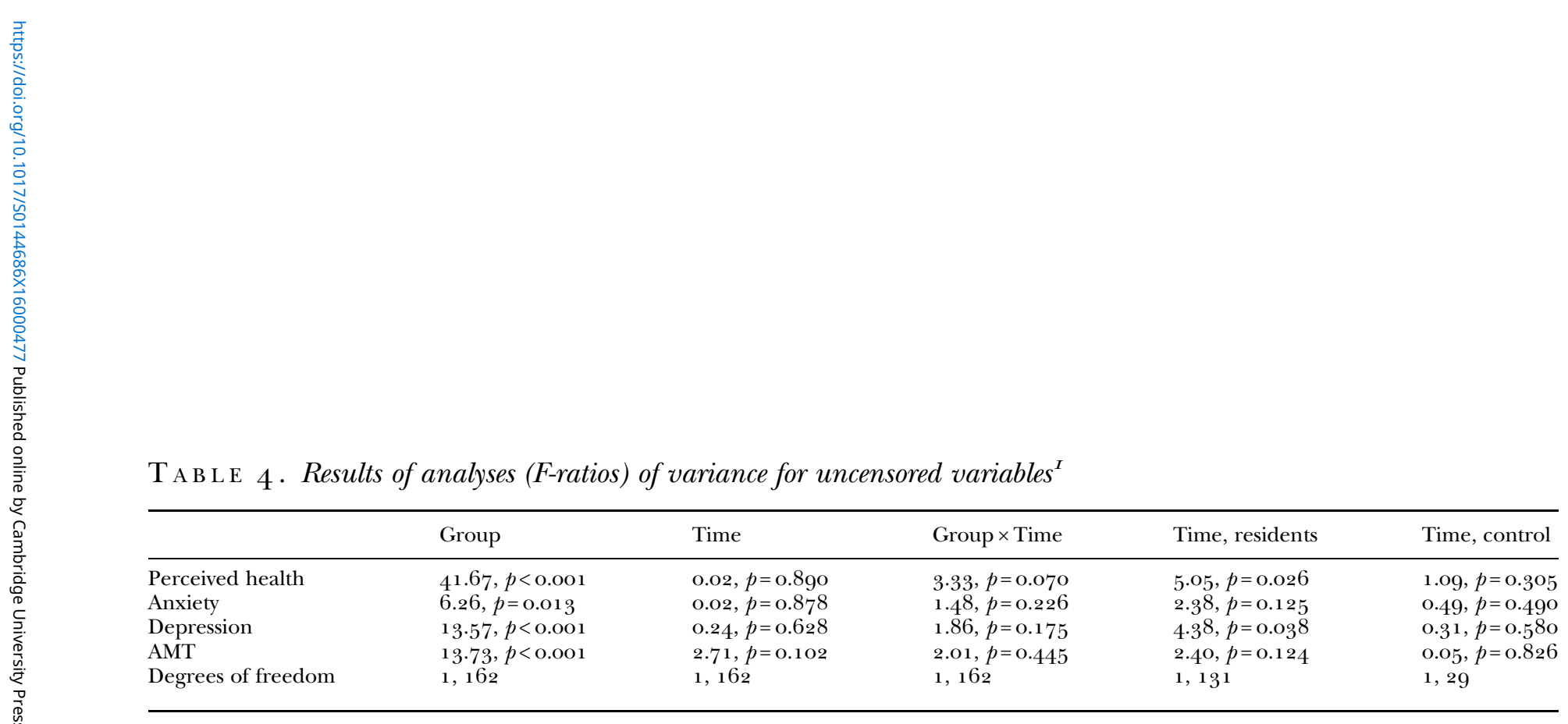

Note. 1. For the autobiographical memory test (AMT) this is analysis of covariance, controlling for age. 
T A в L E 5. Maximum likelihood estimate (MLE) and an estimated 95 per cent confidence interval (95\% CI) for the overall effects and interactions for the two groups

\begin{tabular}{|c|c|c|c|c|}
\hline Variable & Age & Group & Time & Group $\times$ Time \\
\hline & \multicolumn{4}{|c|}{$\operatorname{MLE}(95 \% C I)$} \\
\hline MMSE & $0.13(-0.21,-0.04)^{*}$ & $1.47(-0.27,3.21)$ & $0.32(-0.17,0.81)$ & $0.18(-1.12,1.48)$ \\
\hline ACE-R & $-0.3^{8}\left(-0.5^{8,-0.19) *}\right.$ & $6.35(2.82,9.89) *$ & $1.5^{6}(0.5,2.62)$ & $-0.03(-1.9,1.84)$ \\
\hline Attention & $-0.12(-0.22,-0.03) *$ & $0.3\left(-1.87,2.4^{6}\right)$ & $-0.91(-1.59,-0.23) *$ & $0.12(-1.4,1.64)$ \\
\hline Memory & $-0.1(-0.2,0)$ & $3.67(2.06,5.28) *$ & $1.5(0.78,2.22) *$ & $-1.19(-2.76,0.39)$ \\
\hline Fluency & $-0.13(-0.18,-0.07)^{*}$ & $1.24(-0.06,2.54)$ & $-0.1(-0.46,0.26)$ & $0.36(-0.69,1.4)$ \\
\hline Language & $-0.13(-0.21,-0.05) *$ & $0.24(-1.46,1.93)$ & $-0.3\left(-0.99,0.3^{8}\right)$ & $1.34(-0.3,2.97)$ \\
\hline Visuo-spatial & $-0.07(-0.14,-0.01) *$ & $1.17(-0.15,2.5)$ & $0.5^{2}(-0.07,1.1)$ & $-0.55(-1.77,0.68)$ \\
\hline FLP total & $2.11(-4.92,9.15)$ & $-390.18(-530.66,-249.7) *$ & $-47.9\left(-84.5^{2},-11.28\right)^{*}$ & $194.99(105.59,284.38) *$ \\
\hline IADL & $-0.07(-0.17,0.03)$ & $7.83(5.39,10.27)^{*}$ & $-0.32(-0.67,0.03)$ & $9.73(8.68,10.78) *$ \\
\hline
\end{tabular}

Notes: Model 1 is: $B_{\text {Age }} A+b_{\text {Group }} G+b_{\text {Time }} T+b_{\text {Group } \times \text { Time }} G \times T$. MMSE: Mini-Mental State Examination. ACE-R: Addenbrookes Cognitive Examination Revised. FLP: functional limitations profile. IADL: instrumental activities of daily living.

Significance: * significant effect. 


\section{Carol Holland et al.}

between the two groups as well as the change in the probability of exceeding the censoring threshold (McDonald and Moffitt 1980).

Group effects are given separately for baseline and three months, to determine whether baseline differences are still clear three months later (Hypothesis 2). Negative values signify a lower value for the control group compared to the residents, positive numbers signify a higher score for the control group compared with the residents.

To summarise Tables 2 and 3 , at baseline, when compared to the control group, residents had poorer autobiographical memory (AMT score), were more depressed and anxious, and had poorer perceived health. They also had more functional limitations (FLP), lower levels of independence (IADL), poorer ACE-R scores and poorer ACE-R constituent abilities, notably memory, fluency and visuo-spatial skills. The presence of group differences in the context of controlling for age confirms that these were indeed group differences that were not simply due to the age difference, confirming Hypothesis 1.

When measures were repeated three months later, most effect sizes for these differences reduced (Hypothesis 2). The significant difference in anxiety, $F(1,191)=9.37, p<0.001$, between residents and controls at baseline was no longer significant, $F(1,164)=2.82, p=0.095$ : scores had decreased for residents and fractionally increased for controls. There was a significant difference in language ability after three months that was not there at baseline, and the group effect for visuo-spatial skills at baseline was not significant after three months (see also Table 1 for means). It is noticeable that the group effect for FLP total was much reduced after three months. While at baseline there was a difference of $417.10(95 \% \mathrm{CI}=553.46,280.75)$ in limitations for residents related to controls, by three months this was only an increase of $162.40(95 \% \mathrm{CI}=287.89,36.91)$, which, while still a significant difference, shows a change in level. It must be borne in mind that these coefficients cannot be interpreted directly in the units of the original measure because of the adjustment for censoring to give unbiased estimates of predictor effects.

Given this overall change in FLP, the sub-scales were also examined. These cross-sectional analyses (Table 3 ) revealed lower limitations for controls for all measures at baseline except mobility (items such as 'I do not walk up or down hills') and household management (items such as 'I do not do any of the cleaning that I would usually do'). By three months, this pattern had changed: group differences in social limitations (items such as 'I talk less with other people'), alertness (items such as 'I do not keep my attention on an activity for long'), sleep (items such as 'I sleep or doze more during the day') and communication (items such as 'I speak with difficulty; I get stuck for words, I stutter, stammer or slur my words') were no longer significant. 
Although there are reductions in differences between groups after three months as hypothesised, in order to determine whether such changes are significant, within-participant comparisons across time and time $\times$ group interaction terms were examined (Hypothesis 3). A significant interaction would indicate that one group changed with time in a significantly different manner to the other group. Table 4 illustrates a significant effect of time for depression for residents such that depression reduced over the three months, $F(1,131)=4.38, p=0.038$, but the interaction was not significant, $F(1,161)=1.86, p=0.175$. There was also a significant effect of time for perceived health such that residents perceived their health to be better after three months than they did at baseline, $F(1,131)=5.05, p=0.026$. The interaction showed a marginal effect such that while the residents' perceived health improved, the controls' worsened, $F(1,161)=3.33, p=$ o.070, although the worsening of perceived health for the controls was not significant.

Two different TOBIT models were used to investigate these effects for the censored variables (see Tables 5 and 6). Model 1 (Table 5 ) captures the overall difference between groups - 'Group' measures the difference of the control group from the residents group at baseline. 'Time' measures the effect of time over both groups, Group $\times$ Time measures whether the effect of time is different between the control group and the residents group. There were overall effects of time for ACE-R and its components memory and attention, with memory improving and attention reducing (see means in Table 1), but these changes were no different between groups (no interaction). Group $\times$ Time interactions are significant for FLP total and IADL.

Model 2 (Table 6) captures the effects within the two groups, measuring the effect of 'Age' on the variables for each group separately, and the effect of 'Time' for each group. Findings illustrate improvement in memory for residents, but not controls. Table 6 illustrates that the interaction in FLP shown in Table 5 is explained by an increase with time for the control group in functional limitations $\left(157,95 \% \mathrm{CI}=75^{-240}\right)$, and a reduction (improvement) in limitations for residents $(-48,95 \% \mathrm{CI}=-84,-11)$. Table 6 furthermore suggests that the interaction for IADL is a result of stability for residents (no effect of time), but slightly increasing for controls (improving) $(2.4,95 \% \mathrm{CI}=1.9,2.8)$. There is only an effect of age for the control group.

Given the highly significant interaction for FLP, the eight FLP components used were examined to determine which aspects of everyday functioning limitations improved for residents versus controls. TOBIT analysis was again employed as at least 30 per cent of participants had no scored limitations on each category. Table 7 demonstrates significant Group $\times$ Time interactions for household management, social, alertness and sleep 
T А в L E 6. Maximum likelihood estimate (MLE) and an estimated 95 per cent confidence interval (95\% CI) for the age and time effects for the two groups

\begin{tabular}{|c|c|c|c|c|}
\hline Variable & Age, residents & Age, control & Time, residents & Time, control \\
\hline & \multicolumn{4}{|c|}{$\operatorname{MLE}(95 \% \mathrm{CI})$} \\
\hline MMSE & $-0.1(-0.18,-0.03) *$ & $-0.09(-0.17,-0.01) *$ & $0.32(-0.19,0.83)$ & $0.37(-0.5,1.25)$ \\
\hline ACER & $-0.39(-0.57,-0.21)^{*}$ & $-0.3(-0.48,-0.11)$ & $1.57\left(0.5^{1,}, 2.63\right)^{*}$ & $1.48(0.09,2.86) *$ \\
\hline Attention & $-0.1(-0.19,-0.01)$ & $-0.11(-0.21,-0.02) *$ & $-1.01(-1.72,-0.29) *$ & $-0.13(-0.93,0.68)$ \\
\hline Memory & $-0.11(-0.2,-0.02)^{*}$ & $-0.06(-0.16,0.04)$ & $1.5^{1}(0.78,2.23) *$ & $0.34(-0.98,1.66)$ \\
\hline Fluency & $-0.14(-0.19,-0.08) *$ & $-0.12(-0.18,-0.06) *$ & $-0.1(-0.46,0.27)$ & $0.26(-0.72,1.23)$ \\
\hline Language & $-0.12(-0.2,-0.04)^{*}$ & $-0.12(-0.2,-0.03)^{*}$ & $-0.34\left(-1.04,0.3^{6}\right)$ & $1.1(-0.2,2.39)$ \\
\hline Visuo-spatial & $-0.08(-0.14,-0.01)^{*}$ & $-0.06(-0.13,0)$ & $0.5^{1}(-0.09,1.11)$ & $0.09(-0.82,1)$ \\
\hline FLP total & $2.77(-4.23,9.78)$ & $-2.81(-10.36,4.74)$ & $-48.17\left(-84.81,-11.5^{2}\right) *$ & $157.93(75.43,240.44) *$ \\
\hline IADL & $-0.08(-0.18,0.03)$ & $0.93\left(0.6_{5}, 1.22\right)^{*}$ & $-0.32(-0.67,0.03)$ & $2.4(1.92,2.87) *$ \\
\hline
\end{tabular}

Notes: Model 2 is: $b_{\text {Age }}$ Residents $\times($ Group $=0) \times A=b_{\text {Age }}$ Control $\times($ Group $=1) \times A+b_{\text {Time }} \operatorname{Residents} \times($ Group $=0) \times T+b_{\text {Time }}$ Control $\times($ Group $=1) \times T$. Note that the outcomes have not been normalised and therefore the magnitude of the coefficients cannot be compared between outcomes. MMSE: Mini-Mental State Examination. ACE-R: Addenbrookes Cognitive Examination Revised. FLP: functional limitations profile. IADL: instrumental activities of daily living.

Significance: * significant effect. 
limitations, and Table 8 clarifies that mobility, household management, social and sleep limitations worsened over time for controls (limitations increased) but not for residents, and recreation (items such as 'I take part in fewer community activities'), alertness and communication limitations improved (limitations reduced) for residents but not for controls. Table 8 furthermore illustrates that age was an important contributor for the control group, but not for residents. That is, the impact of age is not significant for residents.

\section{Predicting change in outcomes: functional limitations}

The above data show clearly that total functional limitations reduced for the residents group but that this was focused on the three variables recreation, communication and alertness. In order to determine what predicted these changes for residents (Hypothesis 4), change variables were computed by subtracting scores at follow-up from scores at baseline, and changes in wellbeing (depression, anxiety, perceived health), cognition and the AMT were added as predictors, using a sequential model building hierarchical 'entry' method in a multiple regression analysis (the outcome variable is not censored and so TOBIT modelling is not necessary). Change in limitations in alertness was not significantly predicted by the model $F(9,92)=1.5^{2}$, $p=0.154, R^{2}=0.14$, and no step added a significant proportion of the variance. The overall regression model for change in limitations in communication was not significant, $F(9,92)=1.47, p=0.173, R^{2}=0.14$, but addition of change in AMT as a predictor did produce a significant difference in variance predicted, $F_{\text {change }}(1,87)=7.57, p=0.007\left(\Delta R^{2}=0.08\right)$. That is, the overall model was not significant, but the addition of change in AMT gave a significant change in $R^{2}$. Finally, change in limitations in recreation was significantly predicted by the model, $F(9,89)=2.31, p=0.023, R^{2}=0.21$, with change in cognitive variables (ACE-R sub-components attention, memory, visuo-spatial skills and language) being the key predictors here, producing significant increment in variance predicted $\left(\Delta R^{2}=0.16\right)$. Contrary to expectations, change in the indicator of executive function used, fluency, was not a significant predictor.

\section{Predicting change in outcomes: depression}

Given that depression reduced for residents, psychological factors that may predict change in depression were examined using regression procedures, e.g. it is known that persistent anxiety is a precursor for depression, and that autobiographical memory specificity is also closely associated with depression. Changes in perceived health and anxiety were entered as a wellbeing 
T A B L E 7 . Longitudinal analysis for functional limitations profile (FLP) components for Model I

\begin{tabular}{|c|c|c|c|c|}
\hline FLP component & Age & Group & Time & Group $\times$ Time \\
\hline & \multicolumn{4}{|c|}{$\operatorname{MLE}(95 \% C I)$} \\
\hline Ambulatory & $-0.46(-1.64,0.71)$ & $-96.93(-129.57,-64.28)^{*}$ & $-15.04(-33.27,3.18)$ & $2.05(-49.95,54.04)$ \\
\hline Mobility & $0.09(-1.07,1.25)$ & $-393.33\left(-4^{28.29},-35^{8.36)}\right.$ & $-8.81 \quad(-26.02,8.39)$ & $311.42\left(266.39,35^{6.45}\right)$ \\
\hline Household management & $0.11(-1.14,1.37)$ & $-294.44\left(-332.18,-25^{6.71}\right) *$ & $-12.7\left(-32.91,7.5^{2}\right)$ & $248.53(198.12,298.95) *$ \\
\hline Social & $0.1(-1.16,1.35)$ & $-95.83(-130.73,-60.92)^{*}$ & $-17.96(-36.15,0.22)$ & $61.37(16.37,106.36)^{*}$ \\
\hline Recreational & $0.5(-0.72,1.72)$ & $-78.61(-110.24,-46.98) *$ & $-20.18(-37.27,-3.09) *$ & $3^{6.54}\left(-7.3^{2}, 80.4\right)$ \\
\hline Alertness & $-0.77\left(-2.96,1.4^{1}\right)$ & $-99.68(-155.95,-43.41)^{*}$ & $-66.29(-101.72,-30.86) *$ & $8_{3} .8(0.91,166.7)^{*}$ \\
\hline Sleep & $-1.1(-2.74,0.54)$ & $-170.3\left(-217.23,-123.3^{6}\right)^{*}$ & $-20(-43.91,3.91)$ & $121.48(64.8,178.15)^{*}$ \\
\hline Communication & $0.35(-1.26,1.95)$ & $-107.4^{2}\left(-15^{6.42,-5^{8.41}}\right)^{*}$ & $-30.75(-61.35,-0.14) *$ & $73.4(-2.55,149.35)$ \\
\hline
\end{tabular}

Note: Maximum likelihood estimate (MLE) and estimated 95 per cent confidence interval (95\% CI) are for the overall effects and interactions.

Significance: * significant effect. 
T A B L E 8. Longitudinal analysis for functional limitations profile (FLP) components for Model 2

\begin{tabular}{|c|c|c|c|c|}
\hline \multirow[t]{2}{*}{ FLP component } & \multicolumn{2}{|c|}{ Age } & \multicolumn{2}{|c|}{ Time } \\
\hline & Residents & Control & Residents & Control \\
\hline & \multicolumn{4}{|c|}{$\operatorname{MLE}(95 \% C I)$} \\
\hline Ambulatory & $0.19(-1.33,0.95)$ & $-2.28(-3.69,-0.87) *$ & $-15.47(-32.59,1.65)$ & $-5.3^{2}\left(-91.23,80.5^{8}\right)$ \\
\hline Mobility & $0.04(-1.13,1.2)$ & $-3.73(-5.15,-2.31) *$ & $-7.79\left(-24.8_{5}, 9.26\right)$ & $131.04(122.34,139.74) *$ \\
\hline Household management & $0.16(-1.11,1.43)$ & $-2.67(-4.11,-1.24) *$ & $-12(-32.12,8.13)$ & $133.3(124.3,142.31)^{*}$ \\
\hline Social & $0.34(-0.89,1.57)$ & $-1.47(-2.9,-0.05)^{*}$ & $-18.3^{1}\left(-36.3^{6,-0.26) *}\right.$ & $69.28(21.7,116.86)^{*}$ \\
\hline Recreational & $0.72(-0.48,1.93)$ & $-1.13(-2.54,0.28)^{*}$ & $-20.77(-37.24,-4.29)^{*}$ & $5^{2.66}(-16.57,121.89)$ \\
\hline Alertness & $-0.53(-2.69,1.64)$ & $-2.4(-4.82,0.03)^{*}$ & $-71.5^{6}(-107.18,-35.94)^{*}$ & $59.71(-22.69,142.12)$ \\
\hline Sleep & $-1.12\left(-2.76,0.5^{2}\right)$ & $-4.04(-5.93,-2.14) *$ & $-19 \cdot 5^{1}(-43.62,4.6)$ & $110.18(88.82,131.54)^{*}$ \\
\hline Communication & $0.37(-1.24,1.98)$ & $-1.39(-3.2,0.43)$ & $-30.14(-0.02,-0.25) *$ & $31.07(-57.34,119.48)$ \\
\hline
\end{tabular}

Note: Maximum likelihood estimate (MLE) and estimated 95 per cent confidence interval (95\% CI) are for the overall effects.

Significance: $*$ significant effect. 


\section{$15^{18}$ Carol Holland et al.}

step in a hierarchical entry method multiple regression, followed by change in cognitive function, and then change in the AMT. $R^{2}$ was $0.31, F(8,128)=$ $6.74, p<0.001$. The change in wellbeing contributed significantly to the outcome $\left(\Delta R^{2}=0.26, F_{\text {change }}(2,126)=22.61, p<0.001\right)$. Specifically, within this, change in anxiety was a significant predictor, $p<0.001$. The addition of the cognition step did not add a significant amount of the variance to the total model, but within that, change in the memory sub-component of the ACE-R was a significant predictor of change in depression measure $(t=-2.31, p=0.023)$.

\section{Predicting change in outcomes: cognition}

Given the suggestions from the background literature that changes in anxiety or depression would have an impact on cognitive function, and the positive changes in anxiety and depression for residents, a further regression analysis was conducted to examine the impact on change in the general cognitive function assessment, the ACE-R. $R^{2}$ was $0.05, F(2,127)$ $=3.57, p=0.031$. Change in depression and anxiety were both significant predictors of change in ACE-R, both $p=0.02$.

\section{Discussion}

\section{Initial differences}

These findings are based on the initial transition from moving into an active supported living environment to three months after. Although longer-term influences of lower anxiety or living in a socially accessible and supported community may not yet be apparent, and will be assessed as the project progresses, learning from initial transitions can inform ongoing support and further development, and findings in line with initial hypotheses are apparent. First, there are many significant differences between the control group and the new residents moving into the 'housing-with-care' environment. Residents have poorer perceived health, are more anxious and depressed, and show poorer performance on the socio-emotional measure of memory used, autobiographical specificity. They show significantly poorer cognitive performance, and have poorer scores on independence indices such as the IADL, ADL and on the FLP measures, and although age has an influence on cognitive measures, these group differences are still salient when the age effect is controlled for. These differences are to be expected given that this is a group who have recently made the decision to move to a more supported environment and concurs with findings from parallel qualitative data on the same sample which finds that 'the 
decision to move into ExtraCare was, for many, directly due to concerns and challenges relating to living independently' (Hagger, Shaw and West 2013: 37). Since executive function measures (as indicated here by fluency) have been implicated in planning function, coping strategies, and the autobiographical memory specificity measure (AMT) has been related to wellbeing, depression and ability to cope with trauma, the measures confirm what people are telling us in the qualitative data - those who are moving into these supported living environments do not seem to be coping as well as our control group, independently of any age difference. This is further confirmed by the group effects in measures commonly used to assess independence, coping and need for care, and impact of morbidities on function, the IADL and FLP.

\section{Three months later}

However, data indicate that after a settling in period of about three months in the supported and active environments, some of these group differences have reduced. For example, differences in anxiety and visuo-spatial skills were no longer significant, and residents significantly improved on measures of depression and perceived health. Interactions between time and group indicated that while new residents significantly improved on functional limitations, the control group's limitations increased. Both groups improved on the general cognition measure, the ACE-R (and sub-components memory and attention), as may be expected for a group with low levels of impairment in terms of practice and familiarity effects, although the apparently greater improvement for residents did not result in a significant interaction. There were, however, improvements in the memory subcomponent for residents only. Given the difference in initial status and age, and the conservative nature of tests used (e.g. the use of TOBIT analysis to enable unbiased analysis of censored data and the use of the $95 \% \mathrm{CI}$ values), these findings are important. Moving to an active and supportive environment is essentially a multi-component intervention and the precise aspects of the environment that are the source of these positive effects is unclear, but data from parallel qualitative studies and diary data clearly point to the increase in social interaction, the reduction in isolation, reduction in worries over home maintenance and safety, and an implied sense of personal control and purpose from volunteering in the activities and community functions for those able to do that (e.g. Cooke et al. 2014). For example, Holland et al. (2015) report from the qualitative data that residents reported that volunteering had enabled them to make friends and feel like valued members of the community, and Hagger, Shaw 


\section{Carol Holland et al.}

and West $(2015)$ gave several examples from the qualitative data of reported increase in social engagement, not necessarily to do with specific activities:

You think of home, alone with a husband that's got dementia and can't speak, it's a very lonely life. Your family come, they visit you but they go home. And so I've lost the loneliness and gained all the company and it's the start of a new life. Because when you're looking after somebody like that you haven't really got a life of your own. (Brenda, scheme focus group)

There were significant Group $\times$ Time interactions for the FLP (FLP total limitations) such that the control group's limitations increased but residents' limitations reduced, and for IADL, such that the control group's IADL increased while residents' IADL remained stable. The FLP results are striking and further investigations of its sub-components show clear reductions in communication, recreational and alertness limitations for the residents, in keeping with the hypothesis that living in a socially engaging environment is the source of the positive impact, with many of the FLP items relating to the impact of health on functions such as engagement in interaction or hobbies. At the same time there are increases in difficulties with mobility, household management, social and sleep function for control participants, factors one may expect to be declining with age. Importantly, and perhaps the most noteworthy finding, is that age is not a predictor of FLP components for residents but it is for controls. That is, the effect of increasing age is less influential on function for people living in accessible, active, supported environments. This may be related to the fact that people move there because of their limitations regardless of age, or to the positive influence of the environment which counteracts the effect of age-related difficulties, enabling people to live well even in the context of illnesses and impairments, and further research will enable us to examine this.

The findings in this study combine to form a very strong validation of the impact of an accessible, active and supported environment on wellbeing and perceived functional limitations, regardless of age, with all the further positive effects that may give. Previous work has confirmed the role of social support in improving functional limitations in the contexts of chronic, progressive disease (that is, where limitations would be expected to get worse, not better), e.g. significant symptomatic osteoarthritis (Weinberger, Hiner and Tierney 1986), and these data confirm and extend this concept to demonstrate the impact of a generally supportive and accessible environment as opposed to specific personalised social support interventions. Other previous findings indicate that increased perception of control as a result of support is associated with reduction in functional limitations in people recovering from stroke (Frank et al. 2000) and 
further research could usefully examine the role of perceived control or self-efficacy in the transition period.

\section{Changing relationships}

Predictors of functional limitations were ascertained, with location (extracare environment versus original homes) being the strongest predictor. However, this relationship very significantly changes over time. Where at baseline membership of the residents group predicts more limitations, after three months, it predicts reducing limitations and membership of the control group predicts increasing limitations.

We specifically examined the observed changes in communication and recreational functioning limitations. This is because background literature suggests neuroprotective effects of engagement in social, physical and intellectual activities (e.g. Bennett et al. 2014) and so any limitation in ability to engage in such activities is therefore a serious concern. A change in recreational functioning seemed to be dependent on changes in cognition, and change in communication was predicted by the AMT. This confirms the role of this 'socio-emotional' measure of cognition on such functional limitations and further implies that specific rehabilitation of this function (e.g. Raes, Williams and Hermans 20o9) would have an impact on such important functional limitations. However, contrary to expectations, change in the measure of executive function used, fluency, did not have an impact on changes in functional limitations.

Given the findings, there are clear suggestions as to targets for further interventions to improve functional limitations and social functioning, with autobiographical memory specificity suggested as a target for rehabilitation. Evidence has shown that autobiographical memory rehabilitations can have a significant impact on depression, including in older adults with impairments (e.g. Leontjevas et al. 2013). Further research could usefully examine the impact of such rehabilitation on functioning limitations. The role of depression is also clear, and interventions would potentially have a significant impact on ability to engage and on perceived limitations in independent living. The confirmation of the role of anxiety as a predictor of depression is worth noting ( see e.g. McLeod, Kessler and Landis 1992) addressing anxieties is a crucial component of support. Finally, the roles of attention and memory in the models examined suggest that specific cognitive stimulation aimed at improving these aspects of cognition could be equally valuable, both in terms of predicting reduction of limitations in stimulating functions such as recreational involvement, but also in terms of reducing the impacts of the bi-directional relationships between memory and depression observed. 


\section{Limitations}

A correction for multiple comparisons was not made, which increases the probability of a Type I error. But keeping control over the Type II error probability was considered of greater importance in this study. Findings are limited by the issue of censored ranges in some variables. This restriction was addressed using TOBIT analyses. Nevertheless, all control participants scored at ceiling on the ADL measure, and so analyses were not able to examine this measure of more basic independence activities. However, the FLP includes similar functions and its greater range enabled examination of limitations in independence activities.

Analyses have focused on psychological and independence variables and have not taken into account other factors that inevitably affect the lives and limitations of our participants. Variables such as comorbidities, mobility or sensory impairment may also be having independent effects, although many of their effects will be impacting via the measures used here. Likewise, our analyses do not take into account any measure of the extent to which people's social networks or interaction actually changed, other than the self-reported functional limitation changes evidenced via the FLP, just the fact that such opportunities for interaction were presumed to be far greater for residents than they had been before moving in. However, this is corroborated by qualitative and diary data on the same participants, whereby people reported very significant changes in the simple frequency with which they had any social interaction (Cooke et al. 2014; Shaw, West, Hagger and Holland, 2016).

Nevertheless, findings do suggest that transition to an extra-care environment, and the enrichment and lowering of stresses which that environment may provide, may help to maintain or improve cognitive functioning and psychological wellbeing in older age with related impacts on measures of functional limitations and independence. Future analyses will be able to relate these measures to underlying health indices, to activities engaged in, and to care needs and costs. A final limitation is the small control sample.

\section{Conclusions}

Given accumulation of evidence on benefits of an active and engaged older age, but also on impacts of anxiety and depression on cognitive and independence functioning, this study set out to determine the effects of moving to an active supportive living environment for older adults who were largely experiencing some difficulties or anxieties (with a wide range). Significant reductions in depression and improvement in perceived health were noted for the new residents, as well as improvements in memory and, most saliently, 
in functional limitations. Results suggest that such supported living environments fairly quickly result in improvements in self-reported limitations and small improvements in objectively measured cognition, supporting this type of housing as a positive lifestyle option, and also supporting the concept of population-based 'general' support as opposed to specific targeted interventions only for those with extreme need or in crisis. However, relationships with predictors, particularly autobiographical memory, anxiety and specific components of cognition, suggest that targeted interventions on these aspects will have further consequences for social and recreational engagement, for overall function and the consequent relationships with need for care and support, and quality of life. Finally, data support the notion that functional limitations and wellbeing do not have to be age-related - given the right support and environment.

\section{Acknowledgements}

The authors are grateful to the many wellbeing advisors who facilitated the involvement of the participants, and to all the volunteers who took part in the study. This work was supported by the ExtraCare Charitable Trust as part of a longitudinal project. The financial sponsors played no role in the design, analysis and interpretation of data, or writing of the study. The wellbeing nurses employed by ExtraCare supported the recruitment of the participants, with guidance from researchers, and made their wellbeing health data available, with permission from participants (although that is not used in the present analysis). Ethical approval was given for this study by Aston University Research Ethics Committee, reference number $5^{6} 5$. All ethical guidelines and legal requirements were adhered to.

\section{References}

Alea, N. and Bluck, S. 2003. Why are you telling me that? A conceptual model of the social function of autobiographical memory. Memory, 11, 2, 165-78.

Armstrong, R.A. 2014. When to use the Bonferroni correction. Ophthalmic and Physiological Optics, 34, 5, 502-8.

Beaman, A., Pushkar, D., Etezadi, S., Bye, D. and Conway, M. 2007. Autobiographical memory specificity predicts problem-solving ability in old and young adults. The Quarterly Journal of Experimental Psychology, 6o, 9, 1275-88.

Bennett, D. A., Arnold, S. E., Valenzuela, M. J., Brayne, C. and Schneider, J. A. 2014. Cognitive and social lifestyle: links with neuropathology and cognition in late life. Acta Neuropathologica, 127, 1, 137-50.

Bergner, M., Bobbitt, R. A. and Pollard, W. E. 1981. The Sickness Impact Profile: development and final revision of a health status measure. Medical Care, 19, 8, 787806.

Biggs, S., Bernard, M., Kingston, P. and Nettleton, H. 200o. Lifestyles of belief: narrative and culture in a retirement community. Ageing $\mathcal{E}$ Society, 2o, 6, 649-72. 


\section{Carol Holland et al.}

Bluck, S. 2003. Autobiographical memory: exploring its functions in everyday life. Memory, 11, 2, 113-23.

Brooker, D. J., Argyle, E., Scally, A. J. and Clancy, D. 2013. The enriched opportunities programme for people with dementia: a cluster-randomised controlled trial in 10 extra care housing schemes. Aging and Mental Health, 15, 8, 1008-1017.

Bunce, D. and Murden, F. 20o6. Age, aerobic fitness, executive function, and episodic memory. European Journal of Cognitive Psychology, 18, 2, 22 1-33.

Cooke, R., Kay, A., Wallis, S., Clarkesmith, D. and Holland, C. A. 2014 . Is being active associated with cognitive function, anxiety and depression in older adults living in ExtraCare housing and retirement villages? Paper presented at the UKSBM conference, November, Nottingham, UK.

Croucher, K. 2006. Making the Case for Retirement Villages. Joseph Rowntree Foundation, York, UK.

Department of Health 2005. Independence, Wellbeing and Choice. Available online at https://www.gov.uk/government/uploads/system/uploads/attachment_data/file/ 272101/6499.pdf [Accessed 6 May 2016].

European Commission 2011. Strategic Plan. Available online at http://ec.europa.eu/ research/innovation-union/pdf/active-healthy-ageing/steering-group/implementation_plan.pdf\#view=fit\&pagemode=none [Accessed 6 May 2016].

da Silva, J., Gonçalves-Pereira, M., Xavier, M. and Mukaetova-Ladinska, E. B. 2013. Affective disorders and risk of developing dementia: systematic review. British Journal of Psychology, 202, 3, 177-86.

Dawson, L., Williams, J. and Netten, A. 2006. Extra care housing: is it really an option for older people? Housing, Care and Support, 9, 2, 23-29.

Frank, G., Johnston, M., Morrison, V., Pollard, B. and MacWalter, R. 20oo. Perceived control and recovery from functional limitations: preliminary evaluation of a workbook-based intervention for discharged stroke patients. British Journal of Health Psychology, 5, 4, 413-20.

Hagger, B., Shaw, R. and West, K. 2015 . Loneliness. Factsheet I3, Collaborative Research Between Aston Research Centre for Healthy Ageing (ARCHA) and the ExtraCare Charitable Trust. Aston Research Centre for Healthy Ageing. Available online at http://www. aston.ac.uk/lhs/research/centres-facilities/archa/extracare-project/. [Accessed 6 May 2016

Health Quality 2008. Social isolation in community-dwelling seniors: an evidencebased analysis. Ontario Health Technology Assessment Series, 8, 5, 1-49.

Holland, C. A., Carter, M., Cooke, R., Leask, G., Powell, R., Shaw, R., West, K., Clarkesmith, D., Collins, J., Hagger, B., Kay, A., Lambie, J., Liddell, L. and Wallis, S. 2015. Collaborative Research Between Aston Research Centre for Healthy Ageing (ARCHA) and the ExtraCare Charitable Trust. The Final Report. Aston Research Centre for Healthy Ageing. Available online at http://www.aston.ac.uk/lhs/ research/centres-facilities/archa/extracare-project/ [Accessed 8 September 2015].

Holland, C. A. and Rabbitt, P. M. 1990. Autobiographical and text recall in the elderly: an investigation of a processing resource deficit. The Quarterly Journal of Experimental Psychology, 42a, 3, 441-70.

Holland, C. A., Ridout, N., Walford, E. and Geraghty, J. 201 2. Executive function and emotional focus in autobiographical memory specificity in older adults. Memory, 2o, 8, 779-93.

Howell, D. C. 1987. Statistical Methods for Psychology. Second edition, PWS-Kent, Boston, Massachusetts.

Idler, E. L. and Benyamini, Y. 1997. Self-rated health and mortality: a review of twenty-seven community studies. Journal of Health and Social Behavior, 38, 1, 21-37. 
Katz, S., Ford, A., Moskowitz, R. W., Jackson, B. A. and Jaffe, M. W. 1963. Studies of illness in the aged. The index of ADL: a standardized measure of biological and psychosocial function. Journal of the American Medical Association, 185, 12, 914-19.

Kneale, D. 2013. What role for extra care housing in a socially isolated landscape? London: Housing Learning and Improvement Network. Available online at http:/ /www.ilcuk. org.uk/images/uploads/publication-pdfs/What_role_for_extra_care_housing_ in_a_socially_isolated_landscape.pdf [Accessed 6 May 2016].

Lawton, M. P. and Brody, E. M. 1969. Assessment of older people: self-maintaining and instrumental activities of daily living. Gerontologist, 9, 3, 179-86.

Leontjevas, R. L., Gerritsen, D., Smalbrugge, M., Teerenstra, S., Vernooij-Dassen, M. and Koopmans, R. 2013. A structural multidisciplinary approach to depression management in nursing-home residents: a multicentre, stepped-wedge clusterrandomised trial. Lancet, $\mathbf{3}^{81}, 9^{885}, 2255^{-64}$.

McDonald, J. F. and Moffitt, R. A. 1980. The uses of Tobit analysis. Review of Economics and Statistics, 62, 2, 318-21.

McLeod, J. D., Kessler, R. C. and Landis, K. R. 1992. Speed of recovery from major depressive episodes in a community sample of married men and women. Journal of Abnormal Psychology, 101, 2, 277-86.

Mioshi, E., Dawson, K., Mitchell, J., Arnold, R. and Hodges, J. R. 20o6. The Addenbrooke's cognitive examination revised (ACE-R): a brief test battery for dementia screening. International Journal of Geriatrics Psychiatry, 21, 11 , 1078-85.

Netten, A., Darton, R., Bäumker, T. and Callaghan, L. 201 1. Improving Housing with Care Choices for Older People: An Evaluation of Extra Care Housing. Personal Social Services Research Unit. Available online at www.pssru.ac.uk/projects/echi.htm [Accessed 1 November 2014].

Piccinin, A. M., Muniz, G., Clouston, S., Reynolds, C. A., Thorvaldsson, V., Deary, I. J., Deeg, D. J., Johansson, B., Mackinnon, A., Spiro, A. 3rd, Starr, J. M., Skoog, I. and Hofer, S. M. 2013. Coordinated analysis of age, sex, and education effects on change in MMSE scores. Journals of Gerontology: Psychological Sciences and Social Sciences, 68B, 3, 374-9o.

Piolino, P., Desgranges, B., Benali, K. and Eustache, F. 2002. Episodic and semantic remote autobiographical memory in aging. Memory, 10, 4, 239-57.

Pollard, B. and Johnston, M. 2001. Problems with the Sickness Impact Profile: a theoretically-based analysis and a proposal for a new method of implementation and scoring. Social Science and Medicine, 52, 6, $921-34$.

Raes, F., Williams, J. M. G. and Hermans, D. 2009. Reducing cognitive vulnerability to depression: a preliminary investigation of Memory Specificity Training (MeST) in inpatients with depressive symptomatology. Journal of Behavior Therapy and Experimental Psychiatry 4o, 1, 24-38.

Shaw, R. L., West, K., Hagger, B. and Holland, C. A. 2016. Living well to the end: A phenomenological analysis of life in extra care housing. International Journal of Qualitative Studies on Health and Well-being 1 1, http://dx.doi.org/10.3402/qhw. v1 1.31100.

Tabachnick, B. G. and Fidell, L. S. 2007. Using Multivariate Statistics. Fifth edition, Pearson, Boston, Massachusetts.

Vaida, F., Fitzgerald, A. and DeGruttola, V. 2007. Efficient Hybrid EM for nonlinear mixed effects models with censored response. Computational Statistics and Data Analysis, 51, 12, 5718-30.

Wang, L., Zhang, Z., McArdle, J.J. and Salthouse, T. A. 20o8. Investigating ceiling effects in longitudinal data analysis. Multivariate Behavioral Research, 43, 3, 476-96.

Weinberger, M., Hiner, S. L. and Tierney, W. 1986. Improving functional status in arthritis: the effect of social support. Social Science $\mathcal{E}$ Medicine, 23, 9, 899-904. 
Williams, J. M., Barnhofer, T., Crane, C., Hermans, D., Raes, F., Watkins, E. and Dalgleish, T. 2007. Autobiographical memory specificity and emotional disorder. Psychological Bulletin, 133, 1, 122-48.

Williams, J. M. and Broadbent, K. 1986. Autobiographical memory in suicide attempters. Journal of Abnormal Psychology, 95, 2, 144-9.

Zigmond, A. S. and Snaith, R. P. 1983. The hospital anxiety and depression scale. Acta Psychiatrica Scandinavica, 67, 6, 361-70.

Accepted 30 March 2016; first published online 26 May 2016

Address for correspondence:

Carol Holland,

Aston Research Centre for Healthy Ageing (ARCHA),

School of Life \& Health Sciences,

Aston University,

Birmingham $\mathrm{B}_{4}{ }_{7} \mathrm{ET}$, UK

E-mail: c.holland1@aston.ac.uk 